
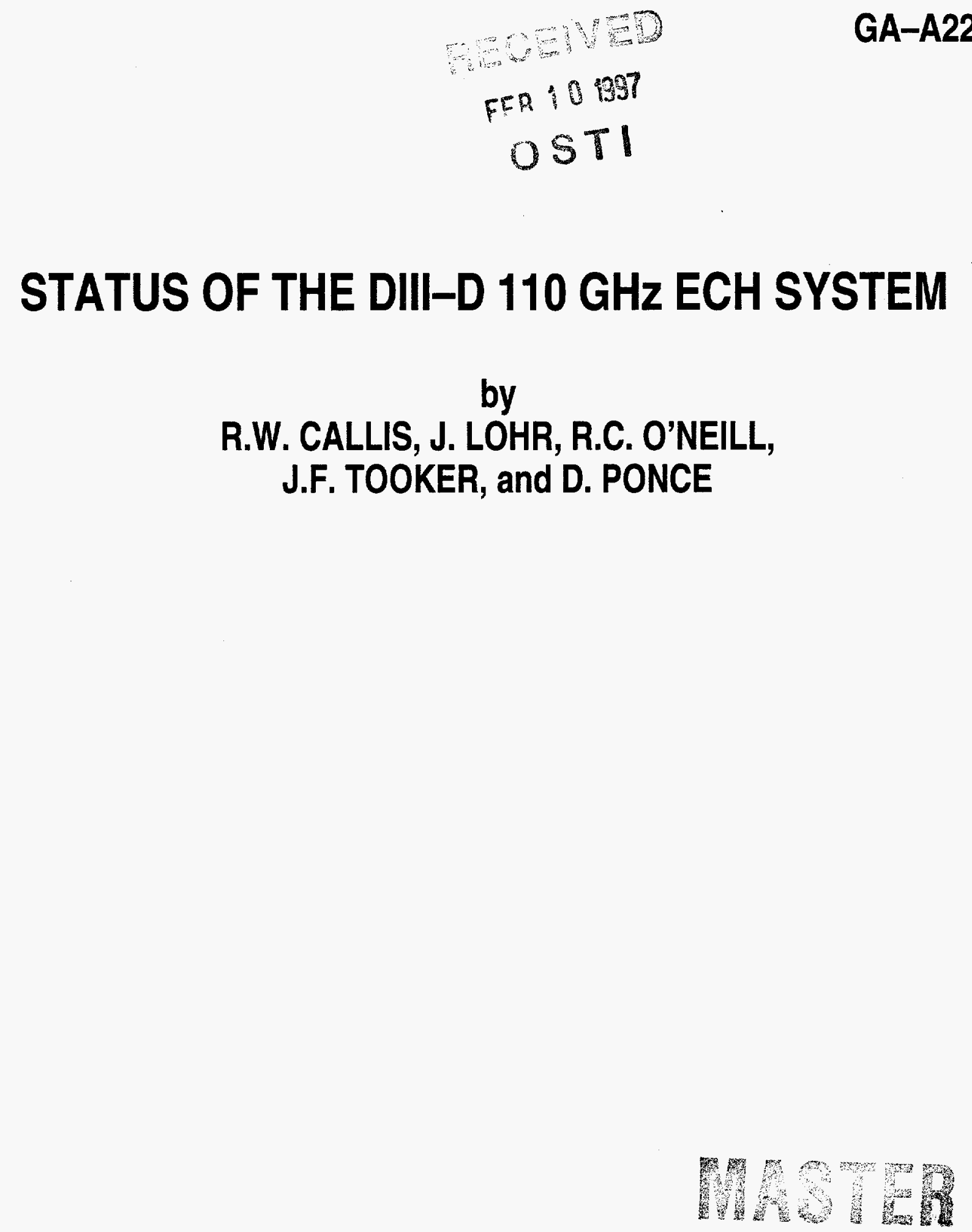

JUNE 1996 


\section{DISCLAIMER}

Portions of this document may be illegible in electronic image products. Images are produced from the best available original document. 


\section{DISCLAIMER}

This report was prepared as an account of work sponsored by an agency of the United States Government. Neither the United States Government nor any agency thereof, nor any of their employees, makes any warranty, express or implied, or assumes any legal liability or responsibility for the accuracy, completeness, or usefulness of any information, apparatus, product, or process disclosed, or represents that its use would not infringe privately owned rights. Reference herein to any specific commercial product, process, or service by trade name, trademark, manufacturer, or otherwise, does not necessarily constitute or imply its endorsement, recommendation, or favoring by the United States Government or any agency thereof. The views and opinions of authors expressed herein do not necessarily state or reflect those of the United States Government or any agency thereof. 


$$
\text { CONF- } 9606116-90
$$

\title{
STATUS OF THE DIII-D 110 GHz ECH SYSTEM
}

\author{
by \\ R.W. CALLIS, J. LOHR, R.C. O'NEILL, \\ J.F. TOOKER, and D. PONCE
}

This is a preprint of a paper to be presented at the Twelfth Topical Meeting on Technology of Fusion Energy, June 16-20 1996, Reno, Nevada, and to be published in The Proceedings.

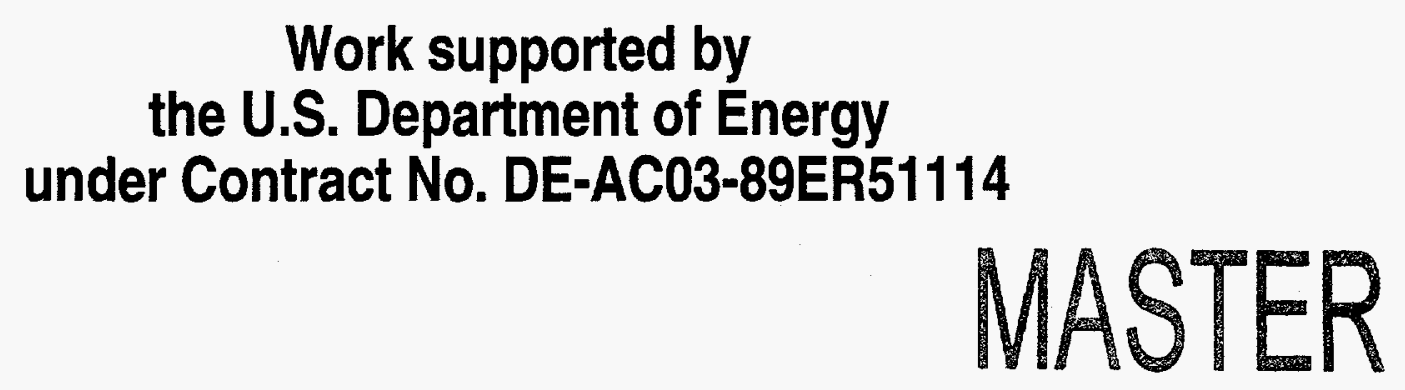

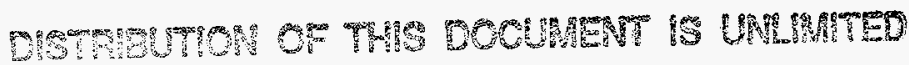

GA PROJECT 3466 


\section{STATUS OF THE DII-D 110 GHz ECH SYSTEM}

R. W. Callis

General Atomics

P.O. Box 85608

San Diego, California 92186-9784

(619)455-3554

\author{
J. F. Tooker \\ General Atomics \\ P.O. Box 85608 \\ San Diego, California 92186-9784 \\ (619) $455-4527$
}

\author{
J. Lohr \\ General Atomics \\ P.O. Box 85608 \\ San Diego, California 92186-9784 \\ (619)455-4519 \\ D. Ponce \\ General Atomics \\ P.O. Box 85608 \\ San Diego, California 92186-9784 \\ (619)455-2919
}

\author{
R. C. O'Neill \\ General Atomics \\ P.O. Box 85608 \\ San Diego, California 92186-9784 \\ (619)455-2659
}

\begin{abstract}
The DIII-D program is presently commissioning the first MW gyrotron of a planned $3 \mathrm{MW}, 110 \mathrm{GHz}$ electron cyclotron heating (ECH) system for off-axis electron heating and current drive. Advanced tokamak (AT) research in DIII-D and other tokamaks requires the ability to control the current density profile. ECH offers the ability to localize the heating and driven current in a controllable manner and is not dependent upon, the local plasma conditions, so it appears to be an ideal tool for AT research. The planned rf sources for the DIII-D system are $1 \mathrm{MW}$ state-of-the-art internal modeconverter gyrotrons, with one gyrotron being manufactured by GYCOM, a Russian company, and two gyrotrons being manufactured by CPI (formerly Varian). The GYCOM gyrotron has been tested at the factory to $960 \mathrm{~kW}, 2$ seconds and has been shipped to GA where it is now undergoing initial checkout and testing. The first CPI gyrotron has been assembled and factory tested to $530 \mathrm{~kW}, 2$ seconds and $350 \mathrm{~kW}, 10$ seconds. Both the Gycom and CPI gyrotrons are limited in pulse length at full power by thermal limits on the output window. The second CPI gyrotron is expected to be ready for testing in April 1996.
\end{abstract}

This paper will report on the initial experiences of using the GYCOM $1 \mathrm{MW}, 110 \mathrm{GHz}$ internal modeconverter gyrotron, at General Atomics, and the observed effects the ECRH power has on the DIII-D plasma.

\section{INTRODUCTION}

Designs of fusion reactors on the basis of conservative extrapolations of presently accepted plasma scaling laws lead to devices that are large and operate at high magnetic fields and large plasma currents, which lead to high capital costs. Recent experiments have identified an enhanced plasma performance regime called Advanced Tokamak (AT) operation, that if produced and maintained could lead to smaller and more attractive fusion power plants.

The DIII-D program has as one of its primary goals to explore these AT regimes, and to demonstrate the ability to sustain these types of plasmas for several relaxation times. In order to implement steady-state AT scenarios, special "tools" are required, particularly rf systems ${ }^{1}$ for controlling the current density and pressure profiles.

Initially, three $110 \mathrm{GHz}, 1 \mathrm{MW}$ rf systems will be installed into the ECH vault at the DIII-D facility of General Atomics. Gyrotrons from $\mathrm{CPI}^{2}$ and $\mathrm{GYCOM}^{3}$ will be procured and tested, with the expectation that by the middle of 1997 three ECH systems will be operational. This report describes the initial startup and operation of the first rf system using a GYCOM gyrotron.

\section{GYCOM GYROTRON}

The GYCOM "Centaur" gyrotron has the same principle design concepts as the earlier gyrotrons $\mathrm{s}^{4,5}$ developed 
for $140 \mathrm{GHz}, 0.5 \mathrm{MW}, 3 \mathrm{~s}$, used in Russia, Germany, Switzerland, etc. The "Centaur". gyrotron is an internal mode-converter gyrotron operating in the $\mathrm{TE}_{19,5}$ mode, with the wave beam exiting perpendicular to the axis of the electron beam. The electron-optical system is designed for a beam voltage of $80 \mathrm{kV}$ and a beam current of up to $50 \mathrm{~A}$. The beam gun is a diode gun with an impregnated emitter, with a maximum current density of up to $4 \mathrm{~A} / \mathrm{cm}^{2}$.

The output window is a single boron nitride disk with a diameter of $145 \mathrm{~mm}$. The rf power is spread more or less evenly over the surface of the window, as shown in Fig. 2; however, since the window is only edge cooled, the central window thermal stresses is the limiting factor for the gyrotron pulse length. Because of the requirement to spread the rf beam uniformly over the output window, the rf beam is not suitable to be injected into a low loss transmission line. Instead an interface unit consisting of two mirrors must be located between the gyrotron and the transmission line so that the $\mathrm{rf}$ beam can be converted from its flat profile into an $\mathrm{HE}_{11}$ waveguide mode, and focused down to the $31.75 \mathrm{~mm}$ diameter used for the DIII-D transmission line system.

The collector uses sweeping of the electron beam along its axis to reduce the thermal loading on the collector walls. The operating parameters of the gyrotron are given in Table 1, and an outline sketch of the gyrotron is shown in Fig. 2.

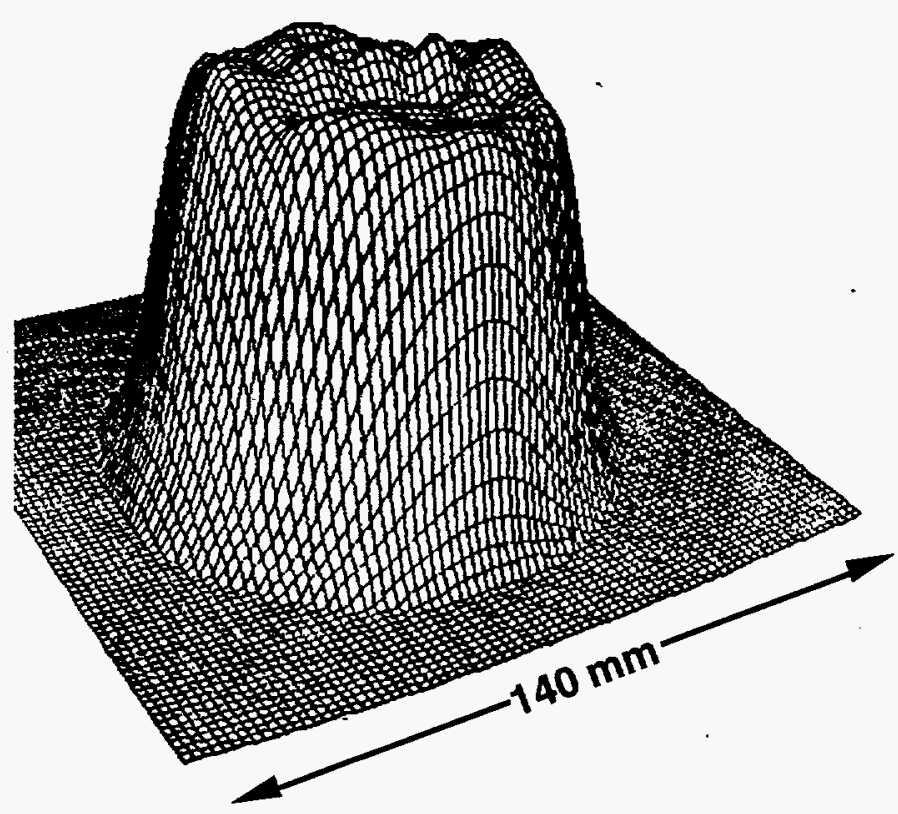

Fig. 1. Calculated rf profile for the $145 \mathrm{~mm}$ diameter BN window.

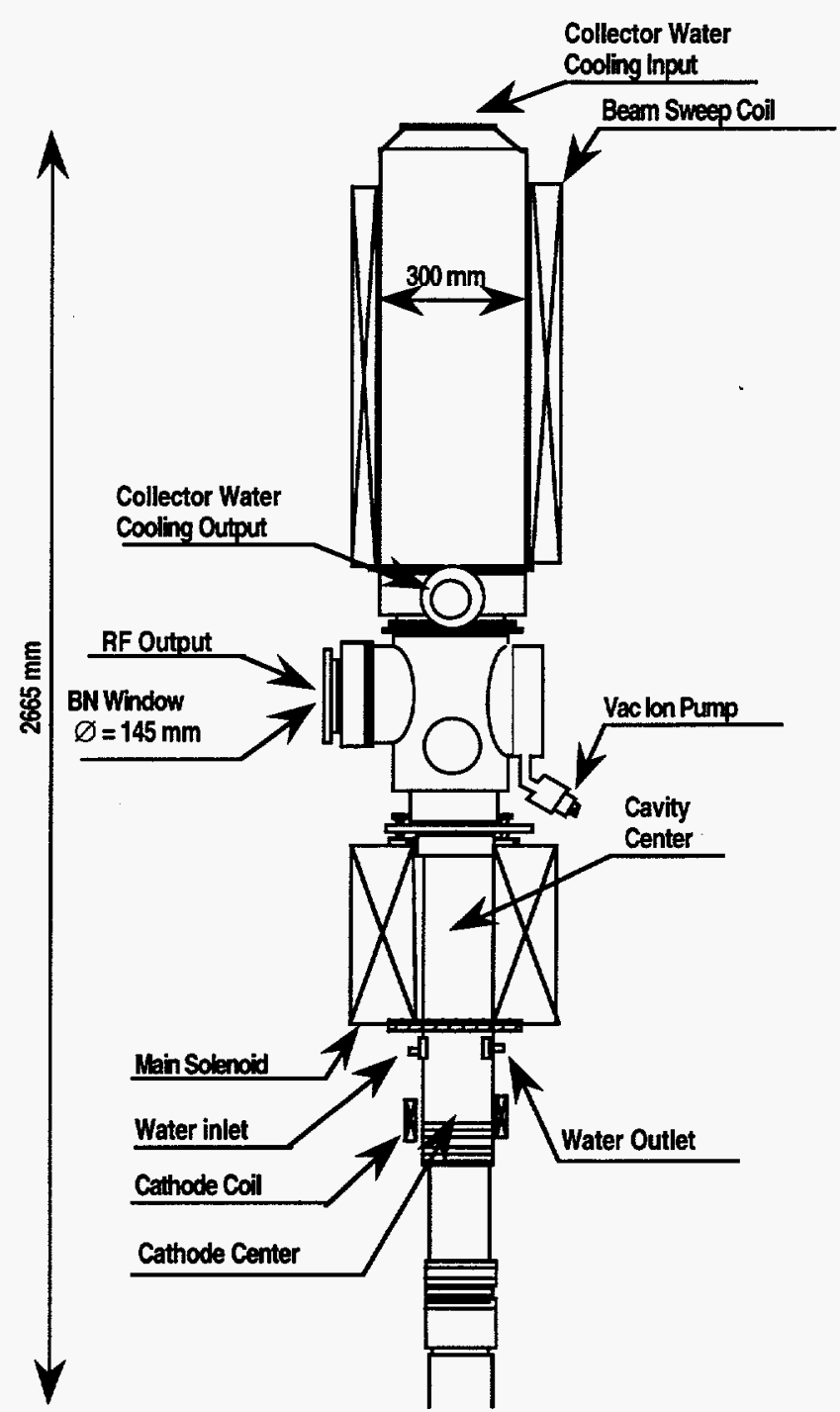

Fig. 2. Outline drawing of the GYCOM "Centaur" $110 \mathrm{GHz}, 1 \mathrm{MW}, 2 \mathrm{~s}$ gyrotron

Table 1

Operation Parameters of the $110 \mathrm{GHz} / 1 \mathrm{MW}$ GYCOM Gyrotron

\begin{tabular}{ll}
\hline Frequency, GHz & $109.8-110.15$ \\
RF output power, $\mathrm{kW}$ & 926.0 \\
RF pulse duration, $\mathrm{s}$ & 2.0 \\
Efficiency, \% & 38.0 \\
Beam voltage, $\mathrm{kV}$ & 72.0 \\
Peak cavity ohmic loss, $\mathrm{kW} / \mathrm{cm}^{2}$ & $\leq 2.0$ \\
Beam current, A & 33.8 \\
Guassian mode content, \% & 88.0 \\
Max. efficiency, \% & 44.0 \\
\hline
\end{tabular}




\section{TEST RESULTS}

\section{A. At GYCOM}

Two tests were performed on the "Centaur" gyrotron in Russia at the Kurchatov Institute: these were a full power, full pulse length test into an open air "brick" load, and a full power short pulse test using the matching optics unit through a short length of corrugated waveguide into a water load.

Measurement of $\mathrm{rf}$ power in the long pulse regime of operation was performed by using the "window energy absorption" method, where the window energy absorption was calibrated to a calorimetric load for pulse lengths up to $0.1 \mathrm{~s}$. At maximum pulse lengths of $2 \mathrm{~s}$, the peak power achieved was $926 \mathrm{~kW}$, with a $38 \%$ conversion efficiency (see Fig. 3). The frequency was observed to shift $350 \mathrm{MHz}$ during the first $300 \mathrm{~ms}$ of the pulse and then become stable at $109.8 \mathrm{GHz}$. For short pulse lengths of $0.05 \mathrm{~ms}$ a peak power of $1.2 \mathrm{MW}$ was obtained at an efficiency of $40 \%$ as shown in Fig. 3.

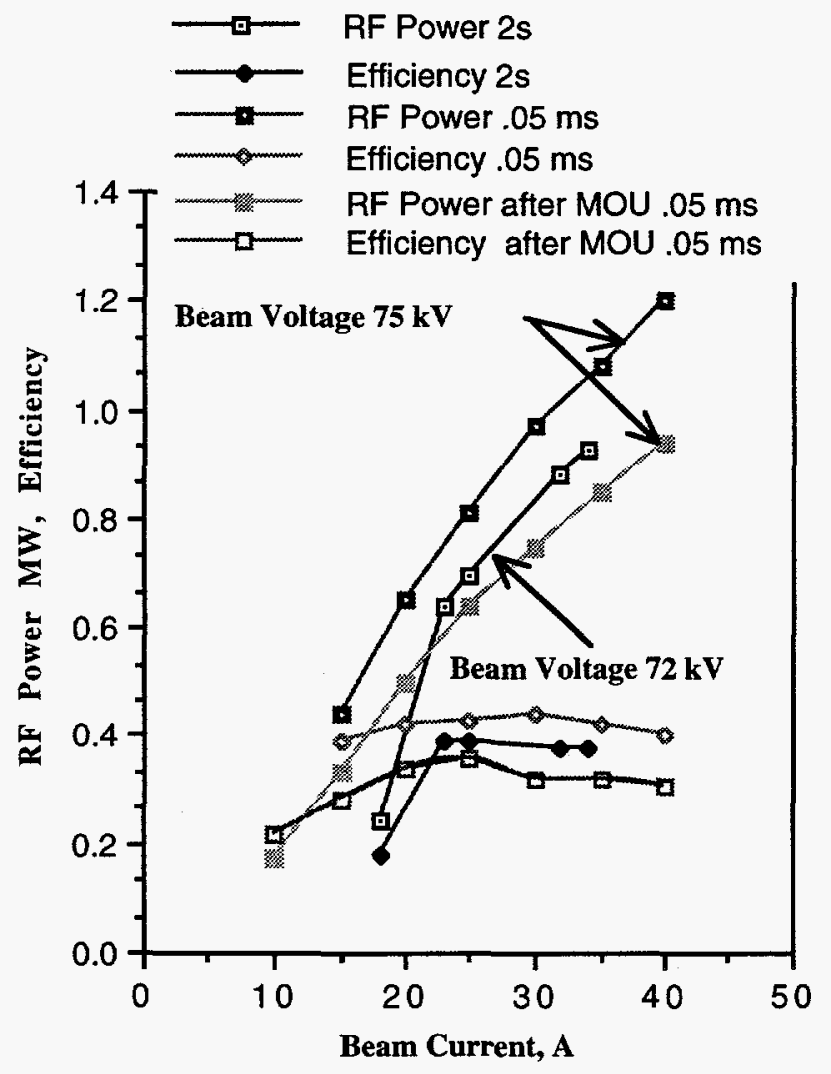

Fig. 3. RF output power and conversion efficiency for the Centaur gyrotron vs. beam current, for pulse lengths of $2 \mathrm{~s}$, and $0.05 \mathrm{~ms}$. And the rf power and efficiency after the mirror optical unit.
To test the ability of the rf power to be injected into a waveguide transmission line, the gyrotron was interfaced to a short length of $33 \mathrm{~mm}$ diameter corrugated waveguide using two mirrors that both focused the $125 \mathrm{~mm}$ diameter rf output beam down to match to the waveguide, and mode convert the beam into an $\mathrm{HE}_{11}$ waveguide mode. The configuration for this test is shown in Fig. 4. Because this test was performed in air the pulse length had to be limited to $2 \mathrm{~ms}$ to avoid waveguide breakdown. The power measured in the calorimetric load placed at the end of the $33 \mathrm{~mm}$ corrugated waveguide was $860 \mathrm{~kW}$ when $960 \mathrm{~kW}$ was measured passing through the BN window. This corresponds to a conversion/transmission efficiency of $88 \%$ $89 \%$. Burn paper measurements at the entrance to and the exit of the waveguide demonstrated high mode purity with the pattern observed being an approximately circular spot.

\section{B. At General Atomics}

The initial tuning of the "Centaur" gyrotron at General Atomics, required a fast responding load that were usable at modest pulse lengths $(20-30 \mathrm{~ms})$, at full power, and could be used for both power measurements and wave beam alignment. The alignment issue arose from the measurements in Russia that identified that the rf beam was not centered on the exit window and deviated from normal by about $1^{\circ}$. Therefore, before the mirror interface tank containing the two focusing/correcting mirrors could be mounted to the gyrotron, the if beam path had to be determined accurately. A short pulse air load was designed and installed in an anachoic chamber. This load, shown in Fig. 5, has a Teflon front surface plate that is faceted with square pyramids approximately 10 free space wavelengths deep with $30^{\circ}$ angles to provide a reasonable match. The back plate is made of TPX (polymethyl-pentene). Between the two plates is octanol, which has an attenuation of $25 \mathrm{~dB}$ through the approximately $1 \mathrm{~cm}$ gap. The octanol facing surfaces of the front and back plates are also cut into square pyramids, but are only five wavelengths deep. The temperature difference between the inlet and outlet is used to calculate the rf power absorbed.

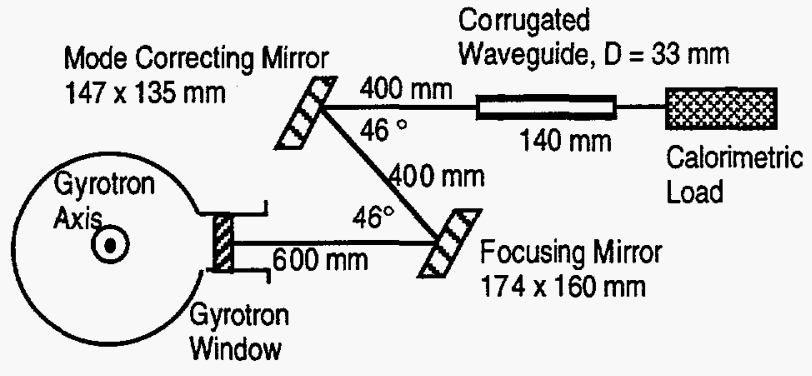

Fig. 4. Gyrotron configuration for waveguide rf insertion test. 


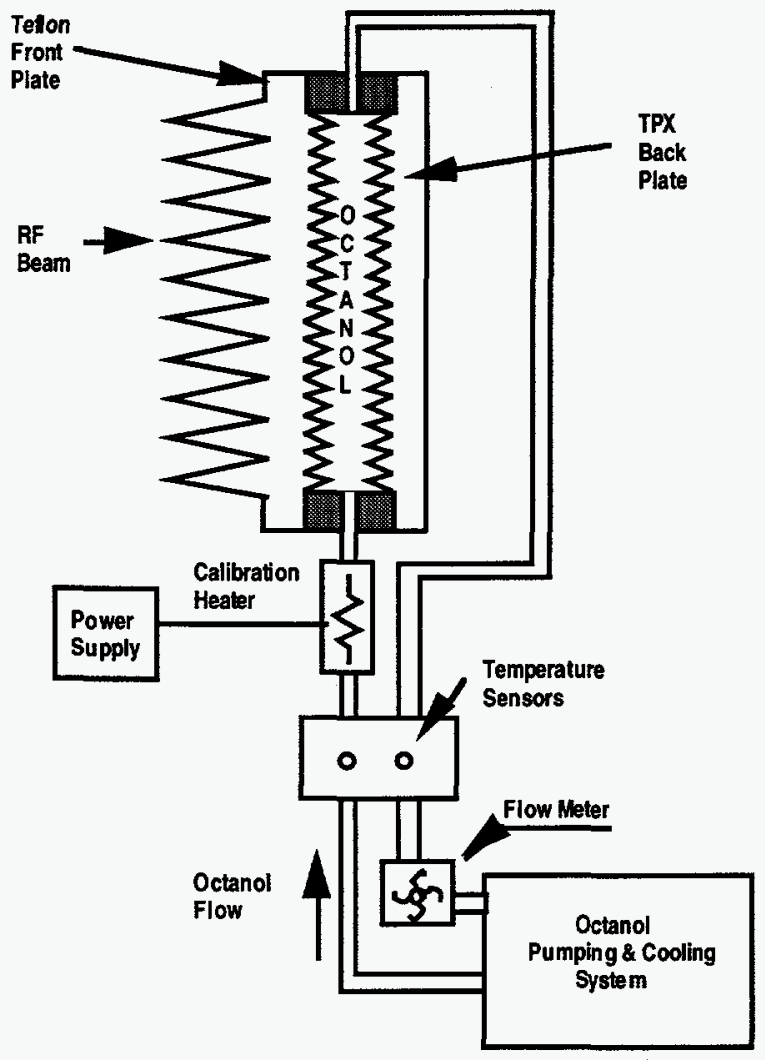

Fig. 5. Diagram of the short pulse octanol load system.

Alignment marks on the load were employed to measure its location relative to the gyrotron window. Using heat sensitive paper mounted to the short pulse load, several "snap shots" of the rf beam were taken at various distances from the gyrotron window. Figure 6 shows the measured pattern at $1724 \mathrm{~mm}$ from the window produced by two $2 \mathrm{~ms}$ long pulses. The results of this set of measurements were that the beam was at an angle of 5.4 milliradians vertically upwards with respect to the normal to the window surface and it was shifted vertically upwards from the center of the window by $4.4 \mathrm{~mm}$. No horizontal offset was detected.

The evacuated ECH waveguide used on DIII-D ${ }^{1}$ imposes constraints on the location and adjusments of the interfacing mirrors. The interfacing mirrors are housed in an Mirror Optical Unit, MOU, that must maintain a vacuum of $10^{-4}$ Toor or better; provide for remote adjusment and alignment of the mirrors, removal of the energy absorbed by the mirrors, and the adsorbtion of any stray if power not coupled to the exit waveguide. ${ }^{6}$ To perform the gyrotron-to-waveguide interface, the two interface mirrors were first located in the MOU on a plane common to the gyrotron window center line and the

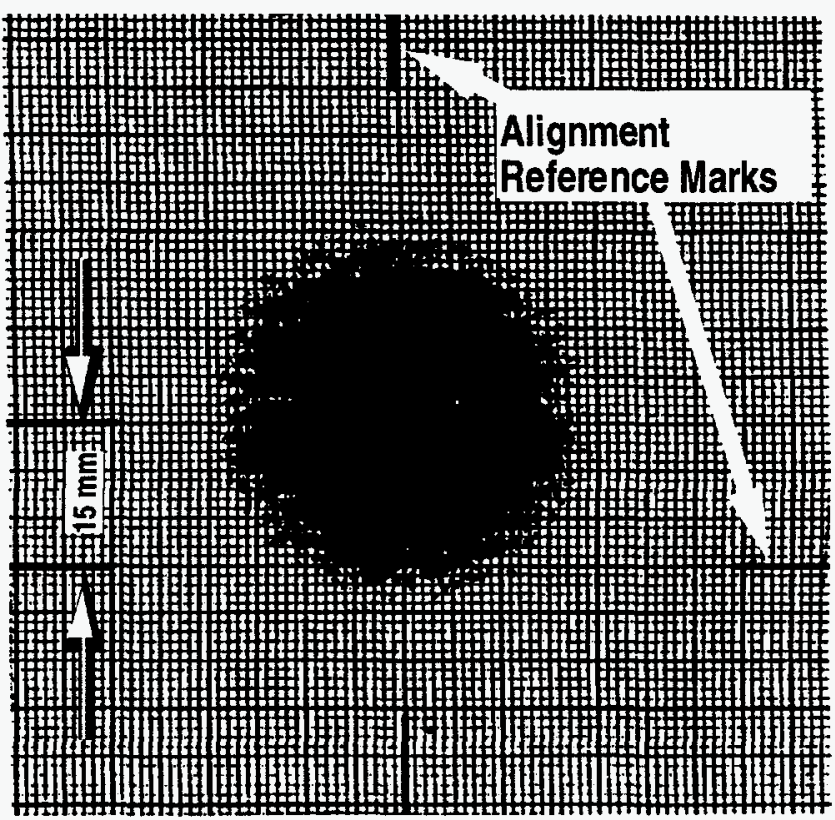

Fig. 6. RF burn paper pattern $1724 \mathrm{~mm}$ from gyrotron window.

exit waveguide centerline, see Fig. 7. The MOU was then aligned to match the if beam path, and the position of the exit waveguide (angular and offset) was adjusted to place the center of the rf at the center of the entrance and exit of the waveguide as determined by patterns on burn paper placed at the two ends of the waveguide (see Fig. 7). Repetitive pulses into the short pulse load demonstrated that over $750 \mathrm{~kW}$ was coupled through the waveguide.

With the mirror interface unit aligned, the exit waveguide was connected to a $31.75 \mathrm{~mm}$ diameter corrugated waveguide system ending in a water-cooled "black body" dummy load. Initial testing into the vacuumload was hampered by the onset of low frequency parasitic oscillations ( 5 to $90 \mathrm{MHz}$ ), ${ }^{7}$ which caused the fault protection circuits to end a pulse after a few milliseconds. With diligence all the interface and control circuits were modified to be shielded from the parasitic noise and testing was resumed.

Pulses up to $200 \mathrm{~ms}$ have been successfully achieved with power measured into the dummy load of $586 \mathrm{~kW}$, with the gyrotron operating at $70 \mathrm{kV}$, and $30 \mathrm{~A}$. This corresponds to an efficiency of $29 \%$, which is close to the $31 \%$ measured in Moscow; 5 little effort has been taken to optimize the gyrotron magnetic field settings, so this agreement is good. 


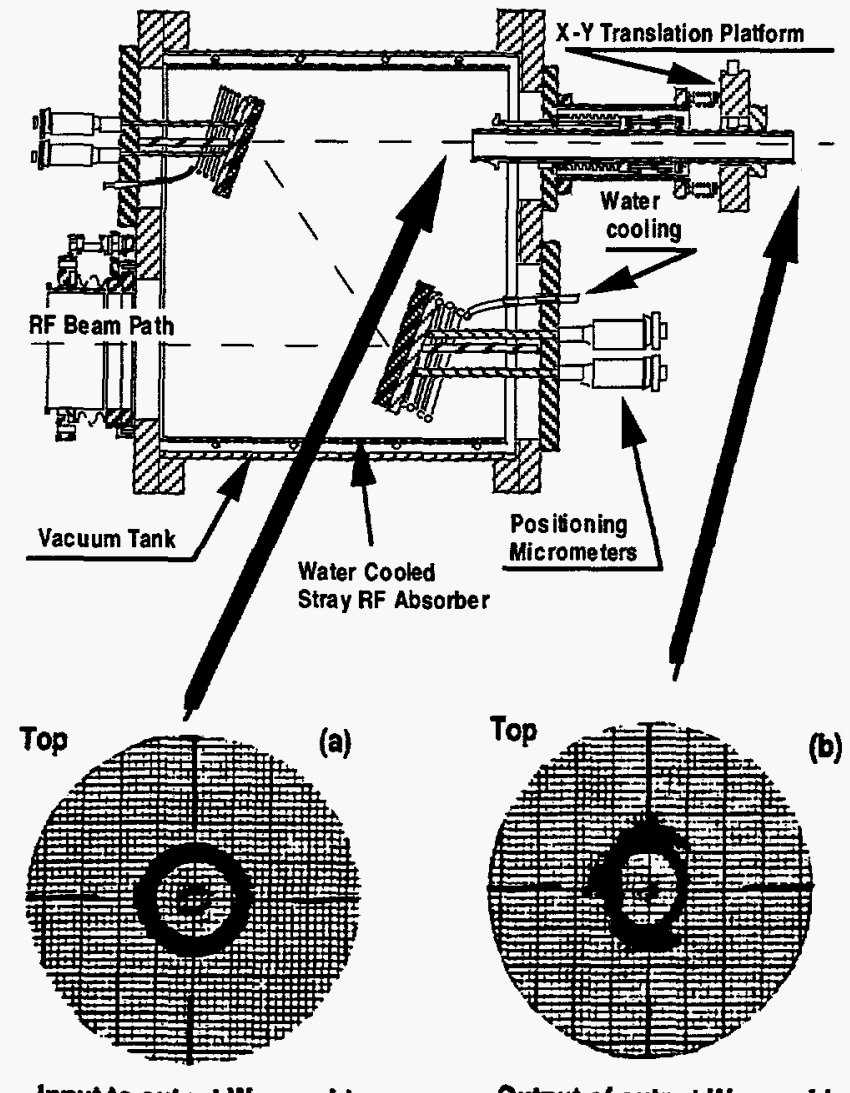

Input to output Waveguide
Output of output Waveguide

Fig. 7. Mirror Optical Unit, which consists of; the interface mirrors, mirror positioning equipment, vacuum tank, stray rf absorber, and the output waveguide assembly. Also shown are the rf burn patterns at the input (a) and the output (b) of the Mirror Optical Unit exit waveguide.

\section{CONCLUSION}

A new generation of megawatt level $110 \mathrm{GHz}$ gyrotrons has been successfully tested both at the vendor and at the user facilities. Power levels of $960 \mathrm{~kW}$ for 2 seconds were demonstrated in Moscow into a brick load demonstrating the tube capabilities, and $750 \mathrm{~kW}$ was measured at General Atomics after the rf beam was compressed and focused into a corrugated waveguide system. The next and exciting step is to use this rf power in plasma experiments.

\section{ACKNOWLEDGMENT}

Work supported by General Atomics internal funding and the U.S. Department of Energy under contract No. DE-AC03-89ER51114.

\section{REFERENCES}

1. R. W. Callis, W. P. Cary, R. C. O'Neill, et al., "Upgrade of the DIII-D RF Systems," Proc. Sixteenth Symposium on Fusion Engineering (1995).

2. K. Felch, P. Borchard, T. S. Chu, et al., "Long Pulse Tests on a High-Power Gyrotron with an Internal, Quasi-Optical Converter," Twentieth International Conference on Infrared and Millimeter Waves, R. Temkin, Editor, Conference Digest, p. 191 (1995).

3. M. V. Agapova, V. V. Alikaev, L. A. Axenova, et al., "Long Pulse $110 \mathrm{GHz} / 1 \mathrm{MW}$ Gyrotron," Twentieth International Conference on Infrared and Millimeter Waves, R. Temkin, Editor, Conference Digest, p. 205 (1995).

4. V. A. Flyagin, A. L. Goldenberg, V. E. Zapevalov, "Advanced Russian Gyrotrons for Plasma Investigations," Nineteenth International Conference on Infrared and Millimeter Waves, K. Sakai and T. Yoneyama, Editors, Conference Digest, p. 77 (1994).

5. V. E. Myasnikov, et al., "Powerful Long-Pulse Gyrotrons of $110 \mathrm{GHz}$ and $140 \mathrm{GHz}$ Frequency Range: Parameters and Characteristics," 7 th Joint Russian-German Meeting on ECRH and Gyrotrons, June (1995).

6. R. C. O'Neill, R. W. Callis, W. P. Cary, et al., "ECH Mirror Interface Tank for $110 \mathrm{GHz}, 1 \mathrm{MW}$ Gyrotron," Proc of the 16th Symposium on Fusion Engineering, (1995).

7. J. Lohr, D. Ponce, L. Popov, et al., "Initial Tests and Operation of a $110 \mathrm{GHz} 1$ Megawatt Gyrotron with Evacuated Waveguide System on the DIII-D Tokamak," Proc. of the Third International Workshop on Strong Microwaves in Plasmas, Moscow, Russia (1996). 